\title{
Proteolytic Processing of the Aplysia Egg-Laying Hormone and R3-14 Neuropeptide Precursors
}

\author{
Robert Newcomb and Richard H. Scheller \\ Department of Biological Sciences, Stanford University, Stanford, California 94305
}

\begin{abstract}
A number of animal behaviors are influenced by the actions of neuropeptides that arise from the processing of complex protein precursors. In this report we investigate the proteolytic processing of neuropeptide precursors expressed in the Aplysia californica bag cells, which govern egg-laying, and neurons R3-14, which mediate aspects of cardiac output. Peptides were purified by fractionation on 2 high-pressure liquid chromatography systems followed by determination of amino acid compositions. Most of these compositions are indicative of processing products derived from the egg-laying hormone (ELH) and R3-14 precursors by cleavage at basic residues. We characterized 9 peptides that arise from the ELH precursor by cleavage of the signal sequence, as well as 7 out of 8 dibasic residues and at least 1 single Arg residue. The peptides range in size from 5 to about 60 amino acids. The R3-14 neuropeptide precursor is cleaved at 2 internal dibasic residues in addition to the signal sequence, resulting in 3 peptides. Shortened forms of several peptides probably result from amino- and carboxy-terminal peptidase action. It is likely that the complex mixtures of neuropeptides arising from these single protein precursors are co-secreted.
\end{abstract}

Neuropeptide precursors are often proteolytically cleaved into multiple peptide products possessing distinct biological actions. Examples include the pro-opiomelanocortin molecule, which is cleaved into fragments with activities ranging from the control of adrenal steroid secretion to a morphine-like activity (Mains et al. 1977), and the Aplysia bag cell egg-laying hormone (ELH) precursor, which contains peptides with distinct actions on isolated neurons (Scheller et al., 1983; Mayeri et al., 1985; Sigvardt et al., 1986). It is thought that the multiple active fragments of a ncuropeptide precursor may act in a coordinated fashion to produce complex physiological and behavioral responses to particular stimuli.

One obstacle to the investigation of this hypothesis has been the complexity of the product mixture generated in the proteolytic cleavage of many neuropeptide precursors. The number of potential cleavage sites on a precursor protein molecule is often

\footnotetext{
Received Apr. 28, 1986; revised Aug. 7, 1986; accepted Aug. 18, 1986.

We wish to thank Ian Cooke for generously donating the use of equipment for this project; also Ronald Taussig, Malladi Shyamala, and Mary Rayson for expert technical assistance. The assistance of Wayne Sossin in aligning the peptides with the precursors is particularly appreciated. This work was supported by a grant to R.H.S. from the NSF. R.H.S. is a Klingenstein Fellow in the Neurosciences and the recipient of a Presidential Young Investigator Award.

Correspondence should be addressed to Richard H. Scheller at the above address.
}

Copyright (C) 1987 Society for Neuroscience $0270-6474 / 87 / 030854-10 \$ 02.00 / 0$ large, and the isolation of all the potential fragments has, in the past, proven to be a difficult technical problem. As a result, studies of the actions of neuronal peptides have thus far focused on easily isolated major cleavage products, sidestepping the task of looking at the entire product mixture secreted by a peptidergic neuron. In view of the additional consideration that the product mixture contained in a peptidergic neuron appears to vary with secretory activity (Fleminger et al., 1984; Akil et al., 1985; Lorenz et al., 1985), our knowledge of the physiological roles of peptidergic neurons is limited by the lack of a complete characterization of the final proteolytic cleavage products.

To understand the information content of peptidergic neurotransmission, it will be necessary to define both the quantitative amounts and physiological activities of all peptides secreted under varying conditions of secretory demand. Defining the complete spectrum of physiological activities of each member of a complex mixture of peptides will probably remain a difficult task for some time to come. With technical advances in high-pressure liquid chromatography (HPLC) instrumentation, it is now possible to completely define the peptides that result from cleavage of some polyprotein precursors. Advances in automated sample handling and subsequent data analysis allow the resolution and characterization of increasingly complex mixtures of proteins and peptides, while advances in solvent delivery systems and fluorescence detectors allow the sensitive detection of released peptide mixtures by direct HPLC methods (Sigvardt et al., 1986).

As a model system to further investigate the biological roles of neurosecretion, the abdominal ganglion of the gastropod mollusc Aplysia californica offers several advantages. Peptides can be assayed directly for effects on identified neurons (Mayeri et al., 1985), thus making the difficult problem of comprehensive physiological characterization approachable. In addition, the genes encoding several neuropeptide precursors expressed in neurons of the abdominal ganglion have been cloned and characterized (Scheller et al., 1984). By determining the nucleotide sequence of genomic or cDNA clones, we have deduced the amino acid sequence of several peptide precursors, thus defining the potential peptide products.

The 271 amino acid precursor encoding ELH is expressed in the bag cell neurons localized in 2 homogeneous clusters on the rostral side of the abdominal ganglion (Mahon et al., 1985). These neurons send secretory processes primarily into the sheath surrounding the ganglion and the pleural abdominal connectives. At least 2 biologically active peptides, ELH and $\alpha$-bag cell peptide $(\alpha-\mathrm{BCP})$, have been purified from bag cell extracts (Chiu et al., 1979; Mayeri et al., 1985; Sigvardt et al., 1986). Furthermore, bag cell discharge leads to a stereotyped egg-laying 
behavior with multiple separate components (Arch and Smock, 1977). By characterizing the effects of peptides on identified neurons it may be possible to describe egg-laying behavior in terms of the summed actions of individual peptides on identified neurons. A prerequisite for these studies is a description of the peptide mixture cleaved from the ELH precursor.

We report here the results of an analysis of peptides obtained from bag cells and the abdominal ganglion using a 2-system reverse-phase HPLC approach. A consistent set of peptides was obtained and appears to account for all but one of the significant cleavage products of the ELH precursor. In addition, we identified several products that arise from a peptide precursor expressed in the R3-14 neurons of the abdominal ganglion. These neurons send processes into the sheath, as well as to the heart, and have roles in modulating cardiac output. The data define the spectrum of peptides potentially secreted by the bag cells and R3-14, thus providing information necessary for physiological studies and further investigations of protein packaging and trafficking.

\section{Materials and Methods}

Instrumentation. A Beckman instrument was used for preparative HPLC separations. This consists of 2 model 112 pumps, a model 210 sample injector ( $2 \mathrm{ml}$ loop), and a model 165 absorbance detector. Amino acid analysis was performed with a Gilson system, including 2 model 302 pumps, a model 231-401 autosampling injector, a model 704 gradient control, and data analysis system. This system utilized Gilson SpectraGlo and Perkin Elmer LS-1 fluorescence detectors. For all first system separations, a $3.0 \times 40 \mathrm{~mm}$ guard column was used. This was removed for the second system separations.

Abdominal ganglion peptides. Abdominal ganglia were dissected from 30 animals $(400-600 \mathrm{gm})$ and the bag cell clusters removed. The tissue was stored at $-70^{\circ} \mathrm{C}$ until used. The ganglia were thawed and immediately boiled for $5 \mathrm{~min}$ in $5 \mathrm{ml}$ of $0.1 \mathrm{~N} \mathrm{HCl}$, homogenized, and then centrifuged at low speed. Multiple $0.8 \mathrm{ml}$ injections were made to load the extract for preparative HPLC ( $1 \mathrm{ml}$ sample loop). Each injection contained $0.6 \mathrm{ml}$ of extract and $0.2 \mathrm{ml}$ of a saturated sodium acetate solution, which was added to neutralize the acid extract. After loading the entire extract volume, peptides were eluted with a linear gradient of $0-100 \%$ methanol $(\mathrm{MeOH})$ in $0.1 \%$ trifluoroacetic acid (TFA) over $90 \mathrm{~min}$ at a flow rate of $1 \mathrm{ml} / \mathrm{min} ; 1 \mathrm{ml}$ fractions were collected. The separation column for this and the second system separations was a $4.3 \times 250 \mathrm{~mm}$ column packed in the laboratory with Vydac $218 \mathrm{TP}$ 54 octadecylsilica (ODS), $10 \mu \mathrm{m}$ particle diameter. At the termination of the experiments reported here, its performance was measured at 1000 plates $/ 250 \mathrm{~mm}$.

The individual $1 \mathrm{ml}$ fractions obtained above were dried to $1 / 2$ to $1 / 3$ original volume with $200 \mu \mathrm{l}$ saturated sodium acetate added to minimize surface adsorbtion. These samples were rechromatographed on a second system using linear gradients of $0-100 \% \mathrm{MeOH}$ over $90 \mathrm{~min}$ in 0.025 $\mathrm{M}$ sodium phosphate, $\mathrm{pH}$ 6.2. Initial peptide detection was by absorbance at 220 and $280 \mathrm{~nm}$. The $1 \mathrm{ml}$ fractions were further characterized by amino acid analysis.

Isolation of bag cell peptides. For this experiment, 50 freshly dissected bag cell clusters from 25 animals (200-400 gm) were homogenized in $4 \mathrm{ml}$ of $\mathrm{HCl}$ : acetone : water $(1: 40: 6)$. The extract was centrifuged at low speed and the resulting supernatent dried to about $1 / 5$ the original volume with nitrogen. Following neutralization with sodium acetate, the extract was injected onto a $4.3 \times 250 \mathrm{~mm}$ ODS column (Vydac 218 TP 54, 5 $\mu \mathrm{m}$ particle diameter). Elution was at $1 \mathrm{ml} / \mathrm{min}$ with a $\mathrm{MeOH}$ gradient of $0-15 \%$ over $20 \mathrm{~min}$, then $15-100 \%$ over $210 \mathrm{~min}$ in 0.025 m sodium phosphate, pH 6.2. Fractions of $1 \mathrm{ml}$ were collected and aliquots subjected to amino acid analysis. Following cvaluation of amounts and purity, fractions were pooled as shown in Figure 1 and rechromatographed. Second system separations were over the same $5 \mu \mathrm{m}$ particle diameter ODS column but with the following gradient of $\mathrm{MeOH}$ in $0.1 \%$ TFA: $0-35 \%$ over $20 \mathrm{~min}, 35-45 \%$ over $10 \mathrm{~min}, 45-65 \%$ over 40 min, $65-75 \%$ over $10 \mathrm{~min}$, and $75-100 \%$ over $10 \mathrm{~min}$. Elution was monitored at 280 and $220 \mathrm{~nm}$. At the end of these experiments, the performance of the separation column was measured at 7000 plates/
$250 \mathrm{~mm}$. This cntire experiment was repeated with bag cell clusters from $25400-600 \mathrm{gm}$ animals. The identical set of peptides was obtained. Amino acid analysis. Peptides were characterized by amino acid analysis essentially as described (Lindorth and Mopper, 1979; Newcomb, 1983). For initial screening of fractions, hydrolysis was peformed in Teflon-stoppered autosampler vials (Alltech no. 95171). For compositional analysis, hydrolysis was done in sealed Pyrex tubes under air with $50 \mu 16 \mathrm{~N} \mathrm{HCl}$ (Sigma) containing 2-5\% anisole (Sigma). Derivatization with $o$-phthaldialdehyde 2-mercaptoethanol was automated with the $231-401$ autoinjector. The reagents (about $10 \mathrm{mg} / \mathrm{ml}$ and $50 \mu 1 / \mathrm{ml}$, respectively) were premixed in $0.5 \mathrm{M}$ potassium borate, $\mathrm{pH} 10$. For each analysis, $40 \mu \mathrm{l}$ of the reagent was added by the autosampler to each hydrolysate. Peptide hydrolysates were loaded onto the autosampler rack (Gilson rack code 9) in 50-70 $\mu$ l water : $\mathrm{MeOH}(3: 1)$. A total injection volume of $80 \mu \mathrm{l}$ was used with an $80 \mu \mathrm{l}$ sample loop. Typically, 50 samples (run over $25 \mathrm{hr}$ ) were loaded with amino acid standards constituting 1 of every 8 analyses. Other analysis conditions were identical to those previously described (Newcomb, 1983) but with amino acid amounts determined from peak area integration performed by the Gilson 704 data analysis system.

\section{Results}

We characterized peptides from bag cell clusters or abdominal ganglia that are cleaved from the ELH and R3-14 neuropeptide precursors utilizing a 2-system reverse-phase HPLC approach to isolate the majority of the predominant peptides. Two different extraction procedures $\left(0.1 \mathrm{~N} \mathrm{HCl}, 100^{\circ} \mathrm{C}\right.$, and acid : acetone: water) and 2 different starting tissues (abdominal ganglia and bag cells) resulted in a reproducible and consistent set of peptides.

To insure that the peptides we isolated correspond to in vivo cleavage products, studies were done to examine the stability of peptides in the extraction mixture. Abdominal ganglia and bag cells were extracted and homogenized in 0.1 and $0.2 \mathrm{~N} \mathrm{HCl}$ at $100^{\circ} \mathrm{C}$, cold $0.2 \mathrm{~N} \mathrm{HCl}$, and $\mathrm{HCl}$ : acetone : water (1:40:6). These mixtures were allowed to incubate at room temperature for $2-3 \mathrm{hr}$ and then examined on HPLC. In the 0.1 and $0.2 \mathrm{~N}$ $\mathrm{HCl}, 100^{\circ} \mathrm{C}$, and the $\mathrm{HCl}$ : acetone: water extracts, the major peptides were stable at all time periods investigated. This was not the case with the cold $0.2 \mathrm{~N} \mathrm{HCl}$ extracts. Therefore, the peptides we characterized are likely to be the result of in vivo processing events. However, some caution must be exercised with the fragments present in minor molar amounts.

An example of the chromatographic pattern obtained from a bag cell extract is shown in Figure 1. Approximately 25 peptide peaks were easily resolved, mostly between 60 and $180 \mathrm{~min}$, corresponding to $\mathrm{MeOH}$ concentrations ranging between approximately 30 and $80 \%$. Chromatographic patterns obtained from abdominal ganglion extracts were similar but exhibited a 5 -fold greater density of peaks. Most of these additional abdominal ganglion peaks were relatively minor compared to those displayed in the bag cell chromatogram.

Because of the complexity of the protein/peptide mixtures, only the predominant peptides were of sufficient purity to be identified on the basis of amino acid composition after a single HPLC separation. As a result, it was necessary to further purify many of the peptides over a second gradient system, as shown in Figure 2 and described in Materials and Methods. As expected, these chromatograms were considerably less complex, in general revealing only 1-4 peaks in the case of bag cells and 1-4 major peaks with many minor peaks in the case of the abdominal ganglion (Fig. 2).

Peptides were characterized by amino acid analysis using the $o$-phthaldialdehyde, 2-mercaptoethanol precolumn derivatization procedure (Lindorth and Mopper, 1979). The advantages 




Figure 1. First-dimension HPLC. Chromatogram of an acid acetone extract of bag cell clusters from 200-400 gm Aplysia california ( $n=25$ ). The gradient is increasing concentrations of methanol in $0.025 \mathrm{~m}$ sodium phosphate pH 6.2 Fractions eluting after the ELH and before II (RLRFD) contain very little peptide material and were not subjected to second system analysis. $R 14$ indicates various peptides from the R14 neuropeptide precursor. Following determination of amounts and purity of protein by amino acid analysis, $1 \mathrm{ml}$ fractions were pooled for second system chromatography. The late eluting fraction of the acidic peptide (peak $R$ ) contains an impurity that does not separate on the second system we used. All other fractions, $A-T$, were rechromatographed on the second system of Figure 2.

of this procedure are that it is rapid and sensitive, and the derivatization procedure can be automated allowing the large number of analyses required for the approach used here. Results of amino acid analysis are given in Table 1.

Given the multiple determinations of each amino acid composition, the data are of sufficient accuracy to allow comparison to amino acid sequences of previously characterized neuropeptide precursors as defined from our analysis of recombinant DNA clones. Two unexpected peptides, which apparently do not derive from previously characterized precursors, were isolated in pure form. These peptides are likely to be of neuronal origin and the composition of the larger, lysine-rich product is presented in Table 1. This peptide was found to elute at 35 and 33 min (Fig. 2, $C, D$ ). The composition of the peptide found in the bag cells is similar to the major abdominal ganglion form of the peptide, which was found in multiple forms. The other peptide is quite small, having the determined composition of Glu: 1 Ser:1 Ala:1. These 3 amino acids occur in characterized abdominal ganglion precursors, including the R3-14 precursor; however, release of this product is not consistent with cleavages at or near basic residues. Both peptides are present in approximately equivalent abundance to the bag cell and R3-14 peptides.

Most of the other compositions obtained are consistent with peptides derived from the ELH and R3-14 peptide precursors
(Table 1; Figs. 3, 4). This might be expected, given that both of these groups of neurons synthesize large amounts of product and send processes to the connective tissue sheath surrounding the ganglion. As a result, comparatively large amounts of peptide are stored in the ganglion rather than being transported to peripheral targets.

For the shorter peptides, the composition data were sufficient to specify exact sequences after comparison with the gene sequence. Minor errors in the analysis did not allow this for the larger peptides, but it was still possible to identify the likely cleavage sites with a high degree of confidence. We discuss cleavage products based on the best fit to the data. These fits predict that all of the longest forms of the peptides arise from cleavage at basic residues and the signal sequence. All peptides are in exact agreement with cleavage at these sites, with the minor exception that some of the determined values for aspartate seem to be off by about 10\%. In Table 1 and Figure 4, we specify the limits of the peptides according to the standard errors of the analysis procedure (see legend Table 1). Peptides from the bag cells were, in general, completely pure, and gave rise to all but one of the ELH precursor compositions given in Table 1. R314 and the major ELH precursor peptides were present in such large quantities in the abdominal ganglion that their amino acid compositions could also be obtained.

The 271 amino acid sequence of the ELH precursor is shown 

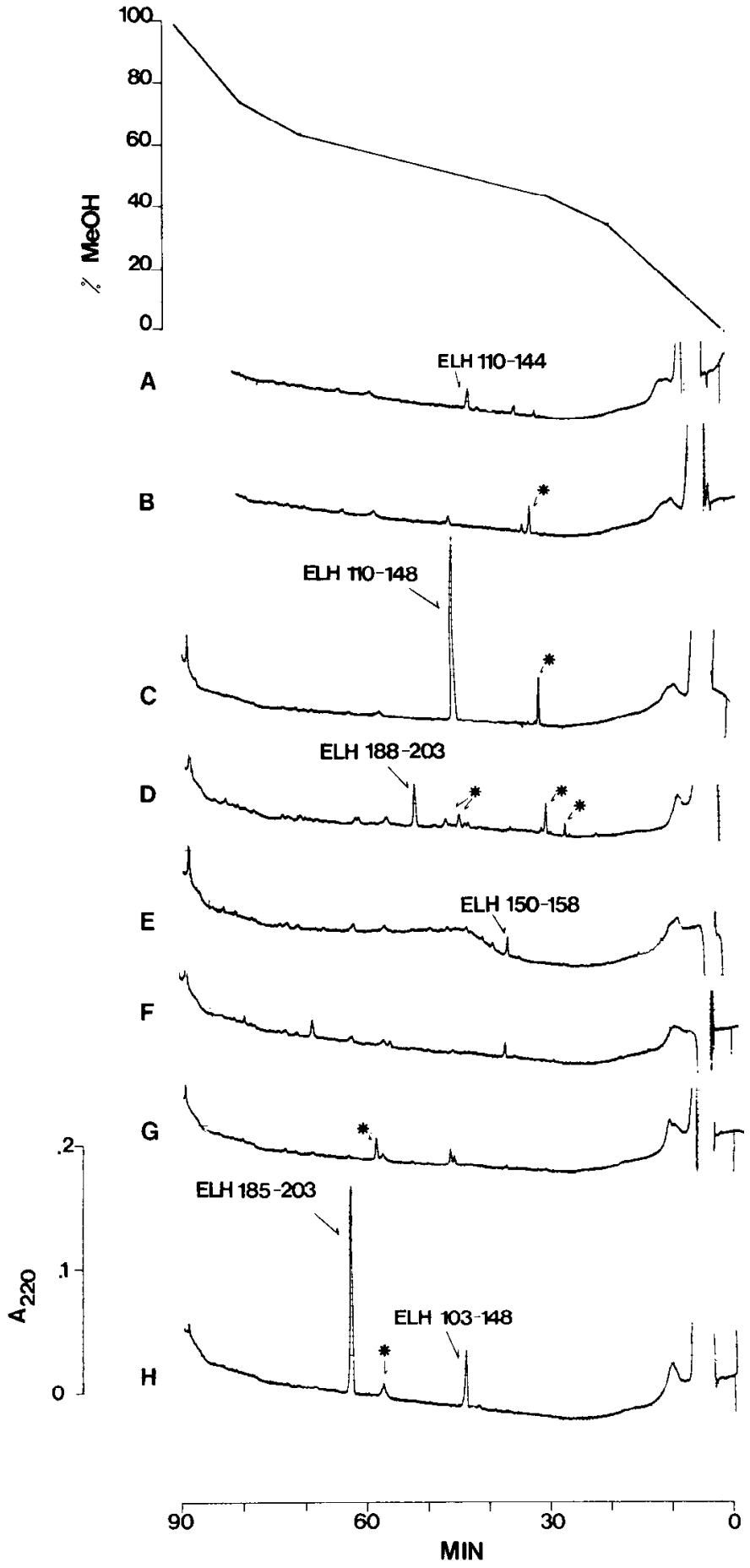
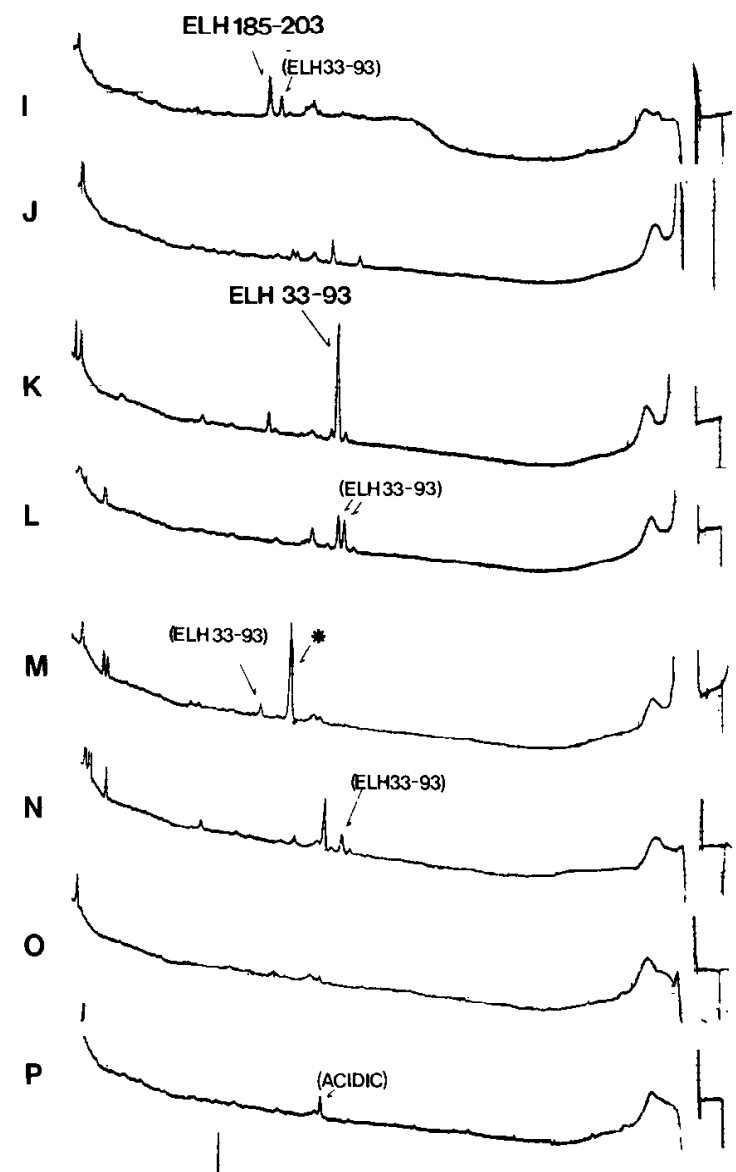

ACIDIC

Q

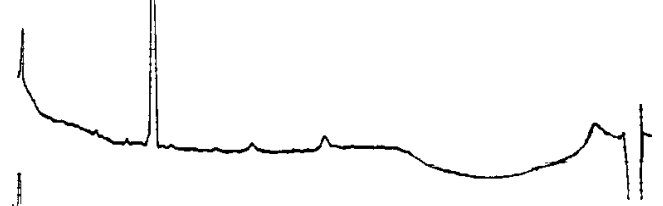

$\mathbf{S}$

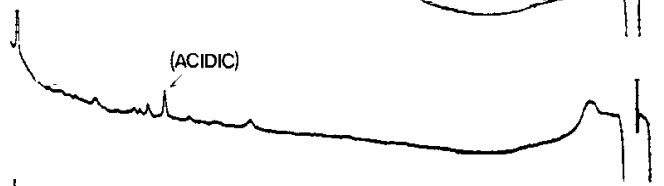

$\mathbf{T}$

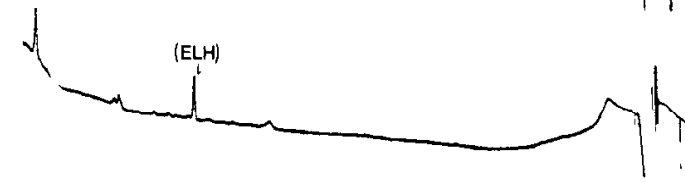

90

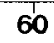

MIN

Figure 2. Second-dimension chromatograms. Fractions $A-T$ from the first chromatographic system were rechromatographed in $0.1 \%$ trifluoroacetic acid with increasing methanol. All detectable $A_{220}$ peaks were subjected to amino acid analysis. Peptides determined to be on the ELH precursor are identified by their position on the precursor; error limits on the analysis are given in Table 1. Peptides present on the ELH precursor that could only be approximately localized are denoted by parentheses. Peptides obviously not on the ELH precursor are denoted by an asterisk. Other peaks are not peptide or were present in insufficient amounts for identification.

in Figure $3 A$. The precursor contains 8 paired basic residues, and our data demonstrate that all but one of these sites are proteolytically processed to generate peptides in the bag cells. In addition to cleavage of the signal sequence, a single arginine residue clearly serves as a processing site in maturation of the product mixture (Figs. 3, 4). These 9 cleavages of the ELH precursor predict the occurrence of 10 peptides. We would not expect to isolate the signal sequence peptide, since, by analogy to other systems, this cleavage is likely to occur on the nascent protein chain while traversing the membrane of the endoplasmic reticulum, followed by fast turnover of the signal peptide. Of the remaining 9 products, 8 were isolated (peptides $\mathrm{K} 1$, I, II, 


\begin{tabular}{|c|c|c|c|c|c|c|c|c|c|c|c|c|c|c|c|}
\hline \multirow{3}{*}{$\frac{\text { Peptide }}{\text { Al }}$} & \multicolumn{5}{|c|}{ Position } & \multirow{2}{*}{$\frac{M_{W}}{3896}$} & \multicolumn{2}{|c|}{$N$} & \multirow[b]{3}{*}{$\mathrm{T}$} & \multirow[b]{3}{*}{$\mathbf{R}$} & \multirow[b]{3}{*}{$\mathrm{V}$} & \multirow[b]{3}{*}{$\mathbf{F}$} & \multirow[b]{3}{*}{ I } & \multirow[b]{3}{*}{$\mathbf{L}$} & \multirow[b]{3}{*}{$\mathbf{K}$} \\
\hline & \multicolumn{5}{|c|}{$\operatorname{ELK} 110(-0,+3)-144(-0,+1)$} & & & 4 & & & & & & & \\
\hline & $\mathrm{D}$ & $\mathrm{E}$ & $\mathbf{S}$ & $\mathbf{M}$ & $\mathrm{H}$ & $\mathrm{G}$ & $\mathrm{T}$ & A & & & & & & & \\
\hline Calc. & 8.4 & 4.4 & 3.8 & + & 0 & 2.5 & 1.2 & 3.5 & 0.81 & 1.9 & 1.9 & 2.5 & 0 & 1.1 & 0 \\
\hline SD & 1.1 & 0.57 & 0.67 & & & 0.63 & 0.10 & 0.49 & 0.24 & 0.43 & 0.20 & 0.53 & & 0.18 & \\
\hline Obs. & 9 & 4 & 4 & 1 & 0 & 2 & 1 & 3 & 1 & 2 & 2 & 3 & 0 & 1 & 0 \\
\hline \multirow[t]{2}{*}{$\mathrm{Cl}$} & \multicolumn{5}{|c|}{ ELH $110(-0,+3)-148(-0,+0)$} & 4408 & \multicolumn{2}{|c|}{14} & & & & & & & \\
\hline & D & $E$ & $\mathrm{~S}$ & $\mathbf{M}$ & $\mathrm{H}$ & $\mathrm{G}$ & $\mathrm{T}$ & A & $\mathbf{Y}$ & $\mathbf{R}$ & V & $\mathbf{F}$ & I & $\mathbf{L}$ & $\mathbf{K}$ \\
\hline Calc. & 8.4 & 5.0 & 3.8 & + & 0 & 2.3 & 1.2 & 3.1 & 0.88 & 2.9 & 1.9 & 2.8 & 0 & 2.0 & 0 \\
\hline SD & 1.5 & 0.50 & 0.42 & & & 0.36 & 0.30 & 0.22 & 0.13 & 0.53 & 0.15 & 0.39 & & 0.18 & \\
\hline Obs. & 10 & 5 & 4 & 1 & 0 & 2 & 1 & 3 & 1 & 3 & 2 & 3 & 0 & 2 & 0 \\
\hline \multirow[t]{2}{*}{ D1 } & & $188(-$ & $+0)-2$ & $(-1$, & & 1564 & & 9 & & & & & & & \\
\hline & D & $\mathrm{E}$ & $\mathbf{S}$ & $\mathbf{M}$ & $\mathbf{H}$ & $\mathrm{G}$ & $\mathrm{T}$ & A & $\mathrm{Y}$ & $\mathbf{R}$ & $\mathrm{V}$ & $\mathbf{F}$ & I & $\mathbf{L}$ & $\mathrm{K}$ \\
\hline Calc. & 0 & 1.9 & 6.4 & 0 & 0 & 2.0 & 0.99 & 0 & 0 & 0 & 0 & 0 & 1.0 & 3.3 & 0 \\
\hline $\mathrm{SD}$ & & 0.41 & 1.2 & & & 0.31 & 0.12 & & & & & & 0.07 & 0.14 & \\
\hline Obs. & 0 & 2 & 6 & 0 & 0 & 2 & 1 & 0 & 0 & 0 & 0 & 0 & 1 & 3 & 0 \\
\hline $\mathrm{El}$ & & $150(-$ & $+0-1$ & $(-0$, & & 1123 & & 5 & & & & & & & \\
\hline & D & $E$ & $\mathrm{~S}$ & $\mathbf{M}$ & $\mathbf{H}$ & $\mathrm{G}$ & $\mathrm{T}$ & A & $\mathbf{Y}$ & $\mathbf{R}$ & V & $\mathbf{F}$ & I & $\mathbf{L}$ & $\mathrm{K}$ \\
\hline Calc. & 0 & 0 & 1.2 & - & 0 & 0.56 & 0 & 1.2 & 0.91 & 2.1 & 0 & 0.88 & 0 & 2.2 & 0 \\
\hline SD & & & 0.23 & & & 0.21 & & 0.28 & 0.18 & 0.18 & & 0.19 & & 0.25 & \\
\hline Obs. & 0 & 0 & 1 & 0 & 0 & 0 & 0 & 1 & 1 & 2 & 0 & 1 & 0 & 2 & 0 \\
\hline $\mathrm{H} 1$ & & $103(-$ & $+4)-1$ & $(-0$, & & 5409 & & 9 & & & & & & & \\
\hline & D & $\mathrm{E}$ & $\mathrm{S}$ & $\mathbf{M}$ & $\mathbf{H}$ & $\mathrm{G}$ & $T$ & A & $\mathbf{Y}$ & $\mathbf{R}$ & $\mathrm{V}$ & $\mathbf{F}$ & I & $\mathrm{L}$ & $\mathrm{K}$ \\
\hline Calc. & 8.2 & 4.9 & 4.4 & + & 0 & 2.9 & 1.4 & 3.5 & 1.0 & 7.7 & 2.0 & 4.0 & 0 & 3.3 & 0 \\
\hline SD & 1.3 & 0.66 & 0.51 & & & 0.59 & 0.27 & 0.36 & 0.18 & 0.81 & 0.09 & 0.51 & & 0.22 & \\
\hline Obs. & 11 & 5 & 4 & 1 & 0 & 2 & 1 & 3 & 1 & 7 & 2 & 4 & 0 & 3 & 0 \\
\hline $\mathrm{H} 2$ & & $185(-$ & $+1)-2$ & $(-1$, & & $1 \overline{8} \overline{6} 3$ & & $\overline{7}$ & & & & & & & \\
\hline & D & $\mathrm{E}$ & $\mathbf{S}$ & $\mathbf{M}$ & $\mathrm{H}$ & G & $\mathbf{T}$ & A & $\mathbf{Y}$ & $\mathbf{R}$ & V & $\mathbf{F}$ & I & $\mathrm{L}$ & $\mathbf{K}$ \\
\hline Calc. & 0 & 1.9 & 6.6 & 0 & 0 & 2.4 & 0.98 & 0 & 0 & 0 & 0.96 & 0 & 0.98 & 4.8 & 0 \\
\hline SD & & 0.51 & 1.0 & & & 0.78 & 0.16 & & & & 0.10 & & 0.09 & 0.75 & \\
\hline Obs. & 0 & 2 & 7 & 0 & 0 & 2 & 1 & 0 & 0 & 0 & 1 & 0 & 1 & 4 & 0 \\
\hline $\mathrm{K} 1$ & & 331- & $+0)-9$ & -6 & & 6718 & & 7 & & & & & & & \\
\hline & D & $\mathrm{E}$ & $\mathbf{S}$ & $\mathbf{M}$ & $\mathrm{H}$ & $\mathrm{G}$ & $\mathrm{T}$ & A & $\mathrm{T}$ & $\mathbf{R}$ & V & $F$ & I & $\mathbf{L}$ & $E$ \\
\hline Calc. & 10.0 & 4.9 & 10.1 & + & 0.85 & 4.0 & 1.3 & 5.0 & 1.8 & 4.0 & 5.3 & 3.8 & 0 & 2.2 & 2.6 \\
\hline SD & 1.8 & 0.79 & 1.4 & & 0.56 & 0.87 & 0.27 & 0.71 & 0.26 & 0.67 & 0.73 & 0.61 & & 0.42 & 1.3 \\
\hline Obs. & 13 & 4 & 10 & 1 & 1 & 4 & 1 & 4 & 2 & 4 & 6 & 4 & 0 & 2 & 3 \\
\hline Q1 & & $245(-$ & $+0)-2$ & $(-0$, & & 2843 & & 5 & & & & & & & \\
\hline & D & $E$ & $S$ & $\mathbf{M}$ & $\mathrm{H}$ & $\mathrm{G}$ & $\mathrm{T}$ & A & $\mathbf{Y}$ & $\mathbf{R}$ & V & $F$ & I & $\mathrm{L}$ & $\mathbf{K}$ \\
\hline Calc. & 4.3 & 4.1 & 4.7 & 0 & 0 & 1.08 & 0.99 & 1.1 & 0 & 1.2 & 1.1 & 0 & 1.08 & 6.2 & 2.06 \\
\hline SD & 0.41 & 0.27 & 0.18 & & & 0.04 & 0.01 & 0.11 & & 0.05 & 0 & 0 & 0.05 & 0.15 & 0.11 \\
\hline Obs. & 4 & 4 & 5 & 0 & 0 & 1 & 1 & 1 & 0 & 1 & 1 & 0 & 1 & 6 & 2 \\
\hline I & & $961-$ & $+0)-10$ & -0 & & 727 & & 3 & & & & & & & \\
\hline & D & $E$ & $\mathbf{S}$ & $\mathbf{M}$ & $\mathbf{H}$ & $\mathrm{G}$ & $\mathbf{T}$ & A & $\mathbf{Y}$ & $\mathbf{R}$ & $\mathrm{V}$ & $F$ & I & $\mathbf{L}$ & $\mathbf{K}$ \\
\hline Calc. & 0 & 0 & 0 & 0 & 0.59 & 0.31 & 0 & 0 & 0 & 2.0 & 0 & 1.0 & 0 & 0.95 & 0 \\
\hline SD & & & & & 0.03 & 0.16 & & & & 0.04 & & 0 & & 0.04 & \\
\hline Obs. & 0 & 0 & 0 & 0 & 1 & 0 & 0 & 0 & 0 & 2 & 0 & 1 & 0 & 1 & 0 \\
\hline II & & 103( & $+0)-1$ & -0 , & & 706 & & 2 & & & & & & & \\
\hline & $\mathrm{D}$ & $\mathrm{E}$ & $\mathbf{S}$ & $\mathbf{M}$ & $\mathrm{H}$ & $G$ & $\mathrm{~T}$ & A & $\mathbf{Y}$ & $\mathbf{R}$ & V & $\mathbf{F}$ & I & $\mathbf{L}$ & $\mathbf{K}$ \\
\hline Calc. & 0.72 & 0 & 0 & 0 & 0 & 0 & 0 & 0 & 0 & 2.0 & 0 & 0.93 & 0 & 1.0 & 0 \\
\hline SD & 0.54 & & & & & & & & & 0.56 & & 0.10 & & 0.25 & \\
\hline Obs. & 1 & 0 & 0 & 0 & 0 & 0 & 0 & 0 & 0 & 2 & 0 & 1 & 0 & 1 & 0 \\
\hline
\end{tabular}




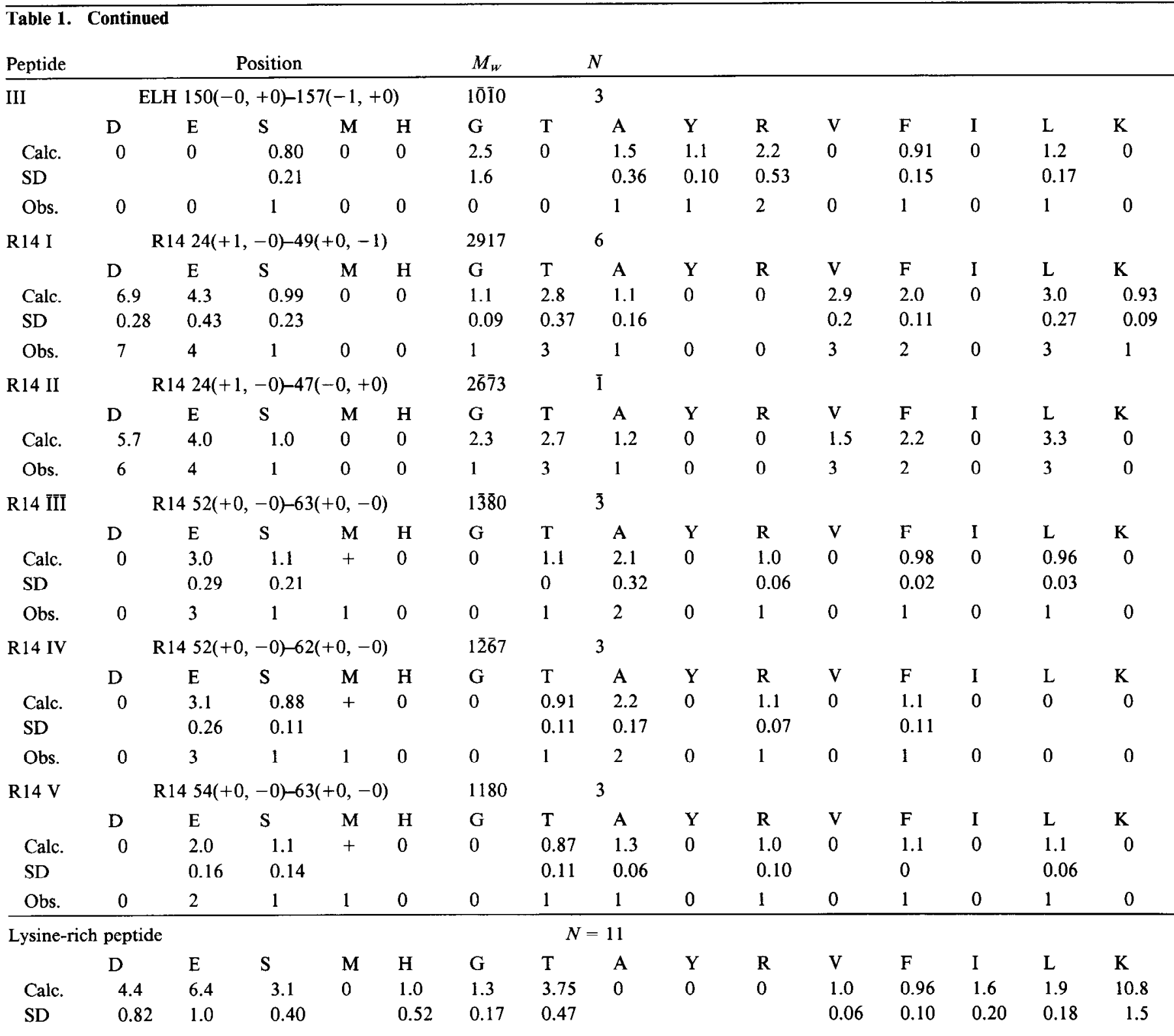

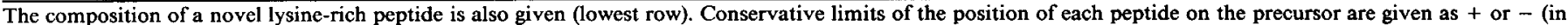

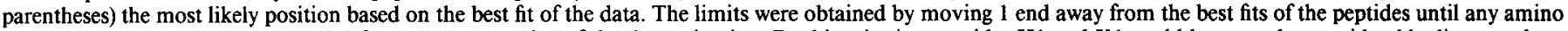

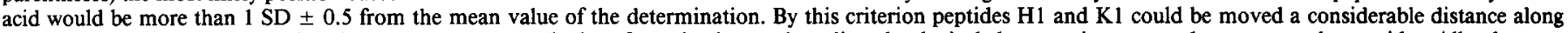

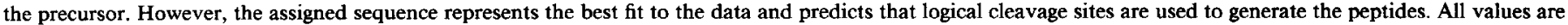

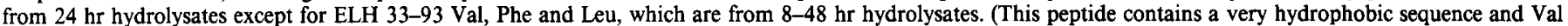

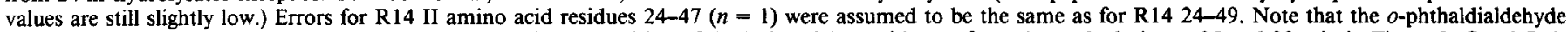

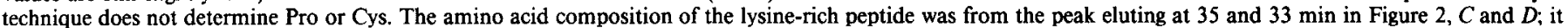
reflects a mixture of very closely related forms of this peptide. All R3-14 peptides were obtained from the abdominal ganglion. All ELH peptides were from the

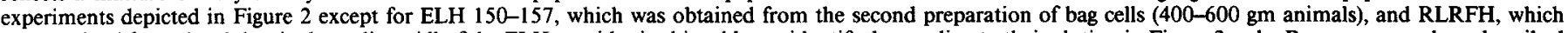

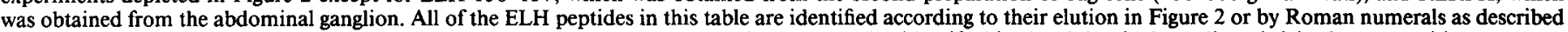

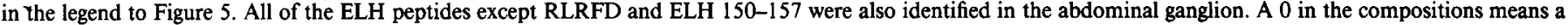
value less than 0.2 ; in general, these values were less than 0.05 .

$\mathrm{Cl}, \mathrm{E} 1, \mathrm{H} 2, \mathrm{~V}$, and Q1), and the ninth (peptide IV, Fig. 4) is presumed to cxist because of the occurrence of both flanking peptides. Peptide IV has a number of charged amino acids and most likely was missed on our chromatographic systems, although we cannot rule out the possibility that it is degraded in vivo. All of the peptides were found in both bag cell and abdominal ganglion extracts with the exception of RLRFD, RLRFH, ELH 150-157, and ELH 110-145. Because of differences in chromatographic procedures and the ways that the fractions were pooled, these peptides were found in only 1 tissue.
A number of shortened forms of the peptides that are cleaved at basic residues were isolated. These peptides most likely arise from either amino or carboxy terminal peptidase activities. An exception is ELH 110-144, which could arise from either cleavage at a single arginine at position 146 or simply carboxy-terminal trimming. Because of the series of control experiments described earlier, it is likely that these peptides arise in vivo and greatly increase the complexity of the peptide product mixture. An additional peptide was found that may represent an intermediate in the processing pathway. Peptide $\mathrm{Hl}$ appears to be 


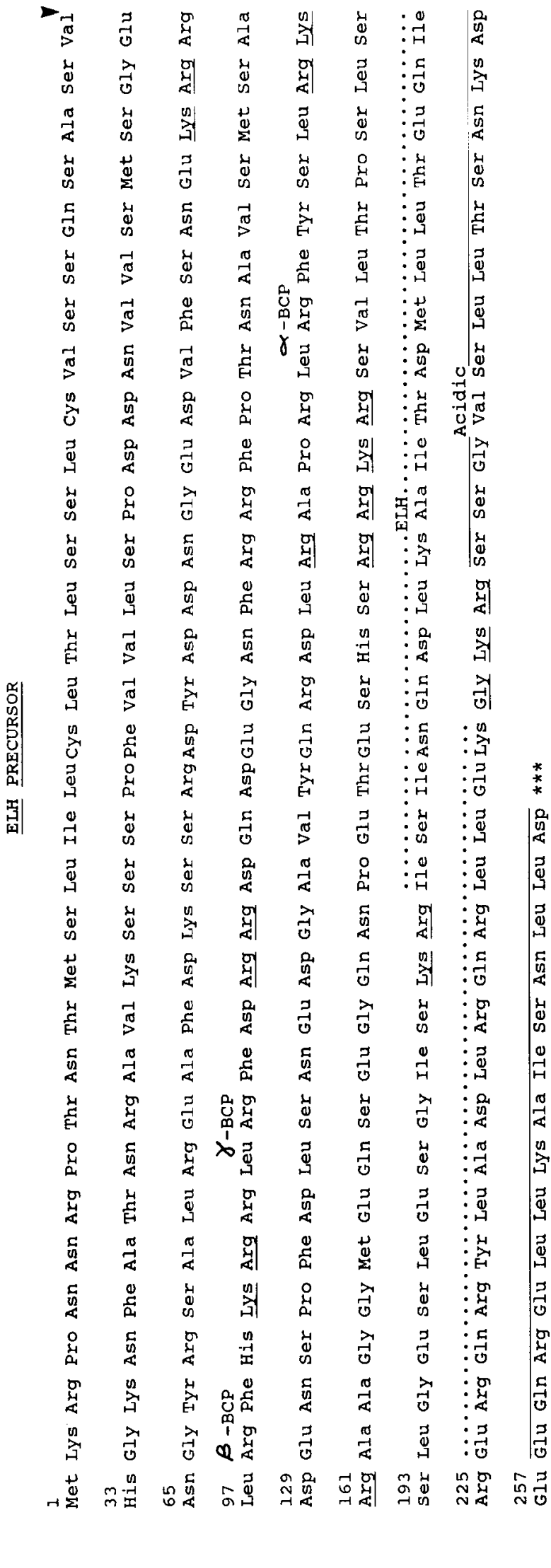

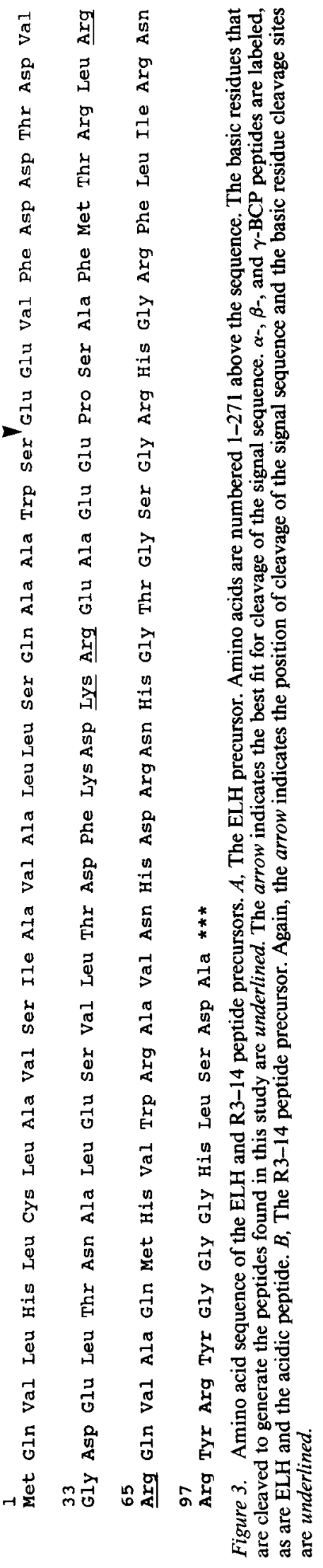



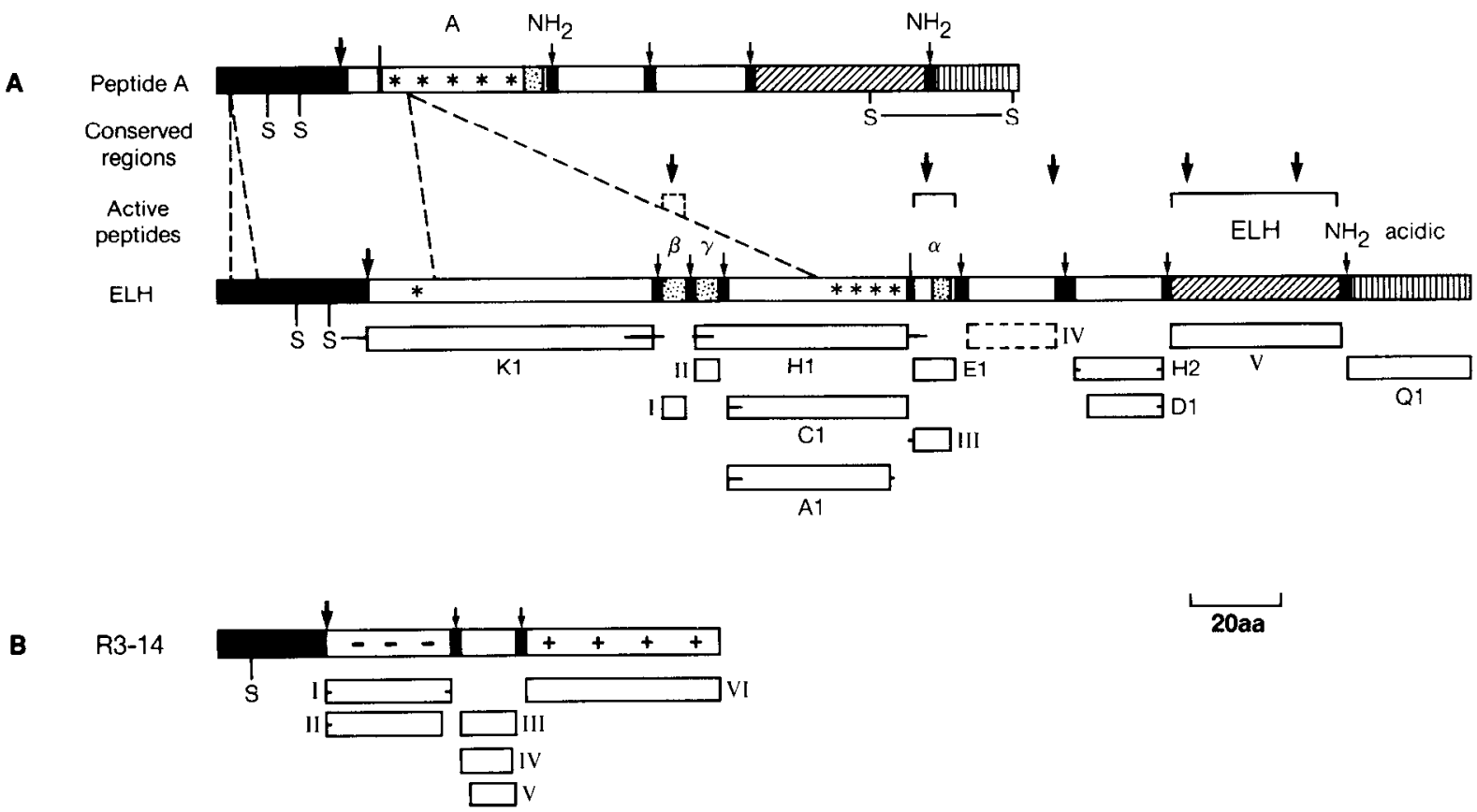

Figure 4. Processing of the ELH and R3-14 peptide precursors. $A$, The ELH precursor. Two related precursors of the ELH gene family are diagrammed. The peptide A precursor is expressed in the atrial gland and the ELH precursor in the bag cell neurons. Dashed lines between the precursors depict regions of insertions and deletions. Large arrows above the precursor denote the location of cleavage of the signal sequence; small arrows and lines are positions of internal proteolytic cleavages that occur at dibasic and single basic residues, respectively. Sequences related to

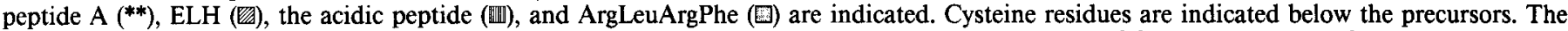
arrows between the peptide A and ELH precursors indicate regions that are conserved between the $A$. californica and $A$. parvula species. The active peptides are indicated by brackets above the ELH precursor. The dashed bracket indicates a suspected active peptide. Each identified cleavage product is indicated as a bar below the ELH precursor. The smaller internal bars demarcate the possible errors in the determination. Each peptide is labeled with an identifying letter corresponding to the second-dimension chromatograph and also a number corresponding to the ELH precursor pcak in that chromatograph. Peptides not found in the set of analyses illustrated in Figure 1 are labeled with Roman numerals $I-V$. Peptide V is the ELH, which was not further characterized. All other peptides were found in other analyses with the exception of peptide IV. All peptides and compositions, as well as errors of the analysis, are summarized in Table 1. B, The R3-14 peptide precursor. The - signs indicate an acidic and the + signs a basic region of the precursor. Cleavage products and other symbols are as in $A$. Peptide VI was previously characterized (Kaldany et al., 1986; Campanelli and Scheller, in press).

comprised of peptides II and $\mathrm{Cl}$ with the ArgArg dibasic at amino acids 108 and 109 uncleaved (Figs. 3, 4). All of the other dibasic residues are LysArg pairs, which suggests that different combinations of dibasics may be processed at different rates. Alternatively, the processing pathway may not be unique, and cleavage at 1 site may preclude cleavage at a second position.

The R3-14 precursor is only 108 amino acids, making its processing considerably easier to interpret. This study identified a series of peptide cleavage products that are consistent with those found by injecting labeled amino acids into neuron R14 followed by isolation and sequencing of the radiolabeled peptide products (Kaldany et al., 1986). Cleavage of the signal sequence occurs after the Ser at position 23, and 2 internal dibasic residues are further processed (Figs. $3 B, 4 B$ ). Various shortened forms of the resulting cleavage products were observed as described above.

\section{Discussion}

We report experiments that define peptide cleavage products arising from the R3-14 and ELH precursor proteins. While we cannot be certain that this study defines complete sets of peptides, all major peaks that elute from our HPLC systems were analyzed. Each precursor gives rise to peptides via cleavage of a signal sequence and internal basic residues. A variety of studies of the processing of these precursors have been reported (Wilson, 1971; Arch, 1972; Loh and Gainer, 1975; Berry, 1976; Aswad,
1978); however, only with the knowledge of the precursor structure afforded by the analysis of recombinant DNA clones have precise studies become feasible.

Previous studies defined the primary sequence of ELH (Chiu et al., 1979), the acidic peptide (Scheller et al., 1983), and $\alpha$-BCP (Rothman et al., 1983). From the precursor structure we predicted additional clcavages that would give rise to peptides we called the $\beta-, \gamma-$, and $\delta$-BCPs. Cleavages that give rise to $\beta$ and $\gamma$-BCP were shown to occur. However, no cleavage at the ArgArg sequence at positions 117 and 118 was noted; thus, no $\delta$ - $\mathrm{BCP}$ was detected. This result is consistent with evolutionary studies demonstrating that $\alpha-, \beta$, and $\gamma-\mathrm{BCP}$ regions are conserved, while the $\delta$-BCP region of the precursor is not found in another species, Aplysia parvula (Nambu and Scheller, 1986). These observations are also consistent with the studies utilizing the $\beta-, \gamma-$, and $\delta$-BCPs that we synthesized based on the DNA sequence (Rothman et al., 1985a, b).

It is worth noting that we did not detect products that would arise via processing at the single Arg residue, which is cleaved in a related gene to generate the biologically active peptide A found in the atrial gland (Fig. 4). This may be due to the existence of different enzymes in the 2 tissues or different conformations of the precursor proteins near this cleavage site. While many single Arg residues are not cleaved, the amino terminal end of the $\alpha$-BCP results from cleavage of such a residue. This points to the importance of surrounding sequences and protein structure in cleavage enzyme recognition. 
Prior to isolation of cDNA and genomic clones encoding the R3-14 peptides, little information was available on the peptides produced in these cells (e.g., Aswad, 1978). This study and our previous work (Kaldany et al., 1986) precisely define the peptide products and illustrate the importance of combining biochemical and molecular genetic studies to define secretory products.

Pulse chase (Kaldany et al., 1986) and peptide isolation approaches yield a consistent picture of the processing of the R3R14 neuropeptide precursor. Cleavage at paired basic residues and removal of these basic residues generates the predominant peptides, while further exopeptidase digestion yields minor products: the intact forms of the precursor amino terminal fragment and central portion were found in near-equal amounts (about $1 \mathrm{nmol} /$ ganglion; see also Rothman et al., 1985a, b; Campanelli and Scheller, in press), with the shortened peptides being minor products.

The peptide products that arise from the ELH precursor were not isolated in stoichiometric amounts, as can be seen by a comparison of peak heights in Figure 1 and consideration of amino acid compositions. Amino acid analysis showed recovery of 3-1 nmol per hag cell cluster of ELH (V), the acidic peptide peptide (Q1), and peptides spanning residues 185-203 (D1 and $\mathrm{H} 2$ ). Peptides spanning residues 33-93 (K1 and various minor products in chromatograms I-N of Fig. 2) and 103-148 (H1, $\mathrm{Cl}$, and $\mathrm{Al}$ ) were recovered in total amounts of $0.1-0.2 \mathrm{nmol}$ per bag cell cluster. $\beta$-BCP was recovered in even lower amounts. The reason for the nonstoichiometric yields may simply be differential recovery of the peptide products after extraction and HPLC separation. Peptide Kl may also be substantially degraded, as a large number of distinct forms of the peptide were obtained.

Electron-microscopic immunohistochemical studies demonstrate the coexistence of $\gamma$-BCP and ELH immunoreactivity in bag cell dense-core granuels (Kreiner et al., 1986). Furthermore, antibodics directed against 3 regions of the R3-14 precursor all react with the same granules. These studies in conjunction with the data presented here suggest that the many, or more likely all, products of the peptide precursors are likely to be co-released. In the case of the bag cells, more than 10 peptides may be secreted simultaneously. While we know at least 2 peptides are active, further physiological analysis must be done before the complete spectrum of activities can be elucidated.

We have recently generated evidence that the basic peptide arising from the carboxy-terminal end of the R3-14 precursor stimulates contractile activity in a variety of muscles in Aplysia (Campanelli and Scheller, in press). In this precursor, it is probably the case that the acidic amino terminal portion of the precursor forms ionic interactions with the very basic, active peptide, thus facilitating packaging into dense-core granules. The R3-14 neurons also may use glycine as a co-transmitter substance (Price and McAdoo, 1981), further expanding the repertory of substances secreted by these cells.

Interestingly, ELH has an amidated carboxy-terminal end, and the active peptide in the R3-14 neurons is blocked at the amino-terminal end, probably by the formation of a pyro-glutamic acid residue (Kaldany et al., 1986). Both peptides are known to be active, and these modifications may serve to protect biologically active products from the amino and carboxy peptidase actions we observed. Alternatively, the $\alpha$-BCP is found in 2 forms differing by single amino acids from the carboxyterminal end. The 1-9 form of $\alpha$-BCP is about 30 -fold less active than the 1-8 form, suggesting, in this case, that the carboxypeptidase activity may be important in generating the active peptide (Rothman et al., 1983). Extension of an active sequence may then have a similar role to amidation in protecting an active-core peptide from degradation. We do not know if any of the other amino or carboxypeptidase trimmed forms of the peptides we characterized have functional significance.

The complex roles of neuropeptides in behavioral processes are only beginning to be understood in cellular and molecular terms. Definition of the processing products resulting from cleavage of the ELH and R3-14 peptide precursors defines the set of peptides involved in mediating egg-laying behavior and cardiac output, respectively, and allows further studies of the complex regulation of posttranslational processing events.

\section{References}

Akil, H., H. Shioma, and J. Matthews (1985) Induction of the intermediate pituitary by stress: Synthesis and release of a nonopioid form of $\beta$-endorphin. Science 227: 424-426.

Arch, S. (1972) Biosynthesis of the egg-laying hormone (ELH) in the bag cell neurons of Aplysia californica. J. Gen. Physiol. 60: 102-119.

Arch, S., and T. Smock (1977) Egg-laying behavior in Aplysia californica. Behav. Biol. 19: 45-54.

Aswad, D. W. (1978) Biosynthesis and processing of presumed neurosecretory proteins in single identified neurons of Aplysia californica. J. Neurobiol. 9: 267-284.

Bcrry, R. W. (1976) Proccssing of low molecular weight proteins by large identified neurons of Aplysia. J. Neurochem. 26: 229-231.

Campanelli, J. T., and R. H. Scheller (in press) Histidine rich basic peptide-HRBP: A cardioactive neuropeptide from Aplysia neurons R3-14. J. Neurophys.

Chiu, A. Y., M. W. Hunkapiller, E. Heller, D. K. Stuart, L. E. Hood, and F. Strumwasser (1979) Purification and primary structure of the egg-laying hormone of Aplysia californica. Proc. Natl. Acad. Sci. USA 76: 6656-6601.

Fleminger, G., L. Lahm, and S. Udenfriend (1984) Changes in rat adrenal catecholamines and proenkephalin metabolism after denervation. Proc. Natl. Acad. Sci. USA 81: 3587-3590.

Kaldany, R-R. J., J. Campanelli, G. Makk, C. J. Evans, and R. H. Scheller (1986) Proteolytic processing of a peptide precursor in Aplysia neuron R14. J. Biol. Chem. 261: 5751-5757.

Kreiner, T., W. Sossin, and R. H. Scheller (1986) Localization of Aplysia neurosecretory peptides to multiple populations of dense core vesicles. J. Cell Biol. 102: 769-782.

Lindorth, P., and K. Mopper (1979) High performance liquid chromatographic determination of subpicomole amounts of amino acids by precolumn fluorescence derivatization with o-phthaldialdehyde. Anal. Chem. 51: 1667-1674.

Loh, Y. P., and H. Gainer (1975) Low molecular weight specific proteins in identified molluscan neurons. I. Synthesis and storage. Brain Res. 92: 181-192.

Lorenz, R. G., C. J. Evans, and J. D. Barchas (1985) Effects of dehydration on pro-dynorphin derived peptides in the neuro-intermediate lobe of the rat pituitary. Life Sci. 37: 1523-1528.

Mahon, A. C., J. R. Nambu, R. Taussig, M. Shyamala, A. Roach, and R. H. Scheller (1985) Structure and expression of the egg-laying hormone gene family in Aplysia. J. Neurosci. 5: 1872-1880.

Mains, R. E., B. A. Eipper, and N. Ling (1977) Common precursor to corticotropins and endorphins. Proc. Natl. Acad. Sci. USA 74: 3014-3018.

Mayeri, E., B. S. Rothman, P. H. Brownell, W. D. Branton, and L. Padgett (1985) Nonsynaptic characteristics of neurotransmission mediated by egg-laying hormone in the abdominal ganglion of $\mathrm{Aply}$ sia. J. Neurosci. 5: 2060-2077.

Nambu, J. R., and R. H. Scheller (1986) Egg-laying hormone genes of Aplysia: Evolution of the EI H gene family. J. Neurosci. 6: 20262036.

Newcomb, R. (1983) Peptides in the sinus gland of Cardisoma carnifex: Isolation and amino acid analysis. J. Comp. Physiol. B. 153: 207-221. 
Price, C. H., and D. J. McAdoo (1981) Localization of axonally transported glycine in vesicles of identified neurons. Brain Res. 219: 307315.

Rothman, B. S., E. Mayeri, R. O. Brown, P. M. Ylan, and E. Shively (1983) Primary structure and neuronal effects of $\alpha$-bag cell peptide: A second candidate neurotransmitter encoded by a single gene in bag cell neurons of Aplysia. Proc. Nat!. Acad. Sci. USA 80: 5753-5757.

Rothman, B. S., K. A. Sigvardt, and E. Mayeri (1985a) Co-release of five peptides, ELH, AP, $\alpha-\beta$ - and $\gamma$-BCP derived from a common precursor protein of the bag cells of Aplysia. Soc. Neurosci. Abstr. 11: 482.

Rothman, B. S., K. A. Sigvart, D. H. Hawke, R. O. Brown, J. E. Shively, and $\mathrm{E}$. Mayeri (1985b) Identification and primary structural analysis of peptide II, an end product of precursor processing in the cells R314 of Aplysia. Peptides 6: 1113-1118.
Scheller, R. H., J. F. Jackson, L. B. McAllister, B. S. Rothman, E. Mayeri, and R. Axel (1983) A single gene encodes multiple neuropeptides mediating a stereotyped behavior. Cell 35: 7-22.

Scheller, R. H., R.-R. Kaldany, T. Kreiner, A. C. Mahon, J. R. Nambu, M. Schaefer, and R. Taussig (1984) Neuropeptides: Mediators of behavior in Aplysia. Science 225: 1300-1308.

Sigvardt, K. A., B. S. Rothman, R. O. Brown, and E. Mayeri (1986) The bag cells of Aplysia as a multitransmitter system: Identification of alpha bag cell peptide as a second neurotransmitter. J. Neurosci. 6: 803-813.

Wilson, D. L. (1971) Molecular weight distribution of proteins synthesized in single identified neurons of Aplysia. J. Gen. Physiol. 57: $26-40$. 